Short Communication

\title{
Response Surface Methodology and Performance Analyses of the Activated Carbon Electrode for Electrosorptive Deionization
}

\author{
Haojie Liu ${ }^{1, *}$, Haihong $\mathrm{Li}^{1}$, Ke Yang ${ }^{2}$ \\ ${ }^{1}$ College of Environmental and Chemical Engineering, Xi'an Polytechnic University, Xi'an 710048, \\ China. \\ ${ }^{2}$ Shaanxi Automobile Commercial vehicle, Baoji 722405, China. \\ *E-mail: ykkm0101m@163.com, 569698405@qq.com
}

doi: $10.20964 / 2020.07 .14$

Received: 17 February 2020 / Accepted: 8 April 2020 / Published: 10 June 2020

\begin{abstract}
When researching the preparation of electrosorption electrodes, many researchers usually activate the material; however, in this study, we directly activated the electrode. An electrosorption electrode made of activated carbon was directly activated by cyclic voltammetry, and the activation conditions were optimized based on the response surface methodology. An optimal model was obtained featuring a sulfuric acid solution concentration of $3.00 \mathrm{~mol} \cdot \mathrm{L}^{-1}$, a scan rate of $0.01 \mathrm{~V} \cdot \mathrm{s}^{-1}$, and a scan cycle of 12.38 , and the model was verified to be reliable. The surface morphology of the electrode material before and after activation was observed by scanning electron microscopy. The results showed that the activated electrode material had abundant pores. The electrochemical properties of the electrosorption electrodes were tested by an electrochemical workstation. The results showed that the specific capacitance of the activated electrode reached $219.98 \mathrm{~F} \cdot \mathrm{g}^{-1}$, which is $127 \%$ higher than the capacitance before activation, and the impedance was reduced from $29.99 \Omega$ to $9.7 \Omega$, and the charge/discharge performance at high current density was good. In addition, the results of the electrosorption deionization experiment indicated that the ion removal rate of the activated electrode was $51.85 \%$, compared with $35.48 \%$ before activation, and the electrosorption capacity of the electrode after activation was significantly improved. This study provides a reference for the development of electrosorption technology.
\end{abstract}

Keywords: Response surface methodology, Electrochemical activation, Electrosorption electrode, Capacitive deionization

\section{$\underline{\text { FULL TEXT }}$}

(C) 2020 The Authors. Published by ESG (www.electrochemsci.org). This article is an open access article distributed under the terms and conditions of the Creative Commons Attribution license (http://creativecommons.org/licenses/by/4.0/). 